\title{
Multiseason recoveries of organic and inorganic nitrogen-15 in tropical cropping
} systems

\begin{abstract}
In tropical agroecosystems, limited $\mathrm{N}$ availability remains a major impediment to increasing yield. A $15 \mathrm{~N}$-recovery experiment was conducted in 13 diverse tropical agroecosystems. The objectives were to determine the total recovery of one single $15 \mathrm{~N}$ application of inorganic or organic $\mathrm{N}$ during three to six growing seasons and to establish whether the losses of $\mathrm{N}$ are governed by universal principles. Between 7 and $58 \%$ (average of 21\%) of crop N uptake duringthe first growing season was derived from fertilizer. On average, $79 \%$ of crop $\mathrm{N}$ was derived from the soil. When $15 \mathrm{~N}$-labeled residues were applied, in the first growing season $4 \%$ of crop $\mathrm{N}$ was derived from the residues. Average recoveries of $15 \mathrm{~N}$ - labeled fertilizer and residue in crops after the first growing season were 33 and $7 \%$, respectively. Corresponding recoveries in the soil were 38 and $71 \%$. An additional $6 \%$ of the fertilizer and $9.1 \%$ of the residue was recovered by crops during subsequent growing seasons. There were no significant differences in total $15 \mathrm{~N}$ recovery (average 54\%) between $\mathrm{N}$ from fertilizer and $\mathrm{N}$ from residue. After five growing seasons, more residue $\mathrm{N}(40 \%)$ than fertilizer $\mathrm{N}(18 \%)$ was recovered in the soil, better sustaining the soil organic matter $\mathrm{N}$ content. Long-term total recoveries of $15 \mathrm{~N}$-labeled fertilizer or residue in the crop and soil were similar. Soil $\mathrm{N}$ remained the primary source of $\mathrm{N}$ for crops. As higher rainfall and temperature tend to cause higher $\mathrm{N}$ losses, management practices to improve $\mathrm{N}$ use efficiency and reduce losses in wet tropical regions will remain a challenge.
\end{abstract}

Keyword: FUE, fertilizer use efficiency, NUE, nitrogen use efficiency, SOM, soil organic matter 